\title{
Penyelesaian Penjadwalan Flexible Job Shop untuk Minimasi Due Windows dengan Algoritma Genetika
}

Ferdinan Rinaldo Tampubolon

Polliteknik Negeri Medan

Email: ferdinantampubolon@ polmed.ac.id

\section{Artikel info \\ Artikel history: \\ Diterima : 15-05-2021 \\ Direvisi : 10-06-2021 \\ Disetujui : 15-06-2021}

Keywords: due windows, flexible job shop; genetika

Kata kunci:

due windows, flexible job

shop; genetik

\begin{abstract}
:
Flexible Job Shop (FJSP) is the development of a job shop where there is more than one machine that can process a job. This study aims to model and complete the FJSP with a due windows objective function where each job must be completed within a certain time span. The method used in this research is the Genetic Algorithm method. The result obtained is scheduling in the form of a Gantt Chart which has a minimum penalty value.
\end{abstract}

\begin{abstract}
Abstrak:
Flexible Job Shop (FJSP) adalah pengembangan dari job shop dimana terdapat lebih dari satu mesin yang dapat memproses suatu pekerjaan. Penelitian bertujuan untuk memodelkan dan menyelesaikan FJSP dengan fungsi tujuan due windows dimana tiap-tiap pekerjaan harus selesai dalam suatu rentang waktu. Metode yang digunakan dalam penelitian ini adalah metode Algoritma Genetika. Hasil yang diproleh adalah penjadwalan dalam bentuk Gantt Chart yang memiliki nilai penalti yang minimum.
\end{abstract}

Coresponden author: Ferdinan Rinaldo Tampubolon Email: ferdinantampubolon@polmed.ac.id artikel dengan akses terbuka dibawah lisensi

CC BY SA 2021

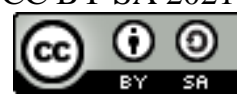

\section{Pendahuluan}

Penjadwalan adalah suatu permasalahan dalam bidang Operasi Riset dimana terdapat sejumlah sumber daya yang terbatas untuk menyelesaikan banyak pekerjaan. Pengambil keputusan harus membuat prioritas untuk memilih pekerjaan yang harus diselesaikan terlebih dahulu berdasarkan tujuan yang akan dicapai (Saudagar, Kamboj, Mohan, Patil, \& Powar, 2020).

Job Shop adalah salah satu jenis penjadwalan dimana sumber daya berupa mesin dan masing-masing pekerjaan mempunyai operasi-operasi yang harus diproses secara berurut oleh satu buah mesin. Flexible Job Shop (FJSP) adalah pengembangan dari Job Shop dimana tiap operasi dapat diproses oleh beberapa mesin. Sehingga waktu pemerosesan dari suatu operasi bergantung pada mesin yang terpilih untuk menyelesaikan operasi tersebut. (Marzouki, Driss, \& Ghédira, 2018). Flexible Job Shop memiliki kerumitan yang lebih tinggi dari Job Shop 
karena yang harus diselesaikan tidak hanya menentukan pekerjaan mana yang harus diselesaikan terlebih dahulu akan tetapi juga mesin yang akan dipilih untuk menyelesaikan pekerjaan tersebut. (Ahmadi, Zandieh, Farrokh, \& Emami, 2016)

Fungsi tujuan yang paling umum dari Job Shop adalah meminimumkan makespan yaitu penyelesaian keseluruhan pekerjaan. Pada kasus tertentu suatu pekerjaan mempunyai prioritas untuk diselesaikan terlebih dahulu. (Alzahrani, 2019). Fungsi tujuan Job Shop yang demikian adalah tardiness, yaitu apabila pekerjaan diselesaikan melebihi waktu yang diberikan maka akan diberikan penalti. Hal ini sesuai dengan keadaan sehari-hari dimana customer sewajarnya akan menunutut kompensasi apabila barang yang diantarkan terlambat. (Kim, Jun, Bang, Shin, \& Choi, 2020). JIT (Just In Time Scheduling) adalah suatu konsep dimana suatu pekerjaan harus diselesaikan sesuai waktu yang ditentukan. Hal ini sesuai dengan realita dimana suatu barang yang diselesaikan terlalu cepat akan membuat barang menumpuk di gudang (earliness). (Idowu, Adamu, \& Sawyerr, 2020). Pada JIT terdapat penalti apabila pekerjaan diselesaikan lebih cepat (earliness) ataupun lebih lama (tardiness) dari waktu yang ditentukan (due date). (Ahmadian, Salehipour, \& Cheng, 2021). Due date yang berupa interval waktu disebut sebagai due windows. Suatu pekerjaan diharapkan dapat diselesaikan pada suatu rentang waktu. Penalti akan diberikan apabila pekerjaan diselesaikan tidak berada pada rentang waktu yang diberikan (Lin, 2020).

Pada penelitian Idowu, Lin, Ahmadian yang sudah dilaksanakan berbasis pekerjaan yang diharapkan dapat diselesaikan pada suatu rentang waktu. Penalti akan diberikan apabila pekerjaan diselesaikan tidak berada pada rentang waktu yang diberikan, konsep tersebut diterapkan pada kasus mesin tunggal (single machine), sedangkan pada penelitian ini konsep tersebut akan diterapkan pada kasus flexible job shop, dimana terdapat beberapa mesin yang dapat menyelesaikan beberapa buah operasi (multi purpose machine) Penelitian ini akan meminimumkan due windows pada penjadwalan FJSP. Model matematis akan dibentuk terlebih dahulu. Selanjutnya model tersebut akan diselesaikan dengan Algoritma Genetika, suatu algoritma yang paling populer untuk menyelesaikan FJSP (Amjad et al., 2018). Penggunaan elite strategy maupun dispatching rule pada insialisasi populasi akan menghasilkan penjadwalan FJSP dengan penalti yang minimum.

\section{Metode Penelitian}

Penelitian ini merupakan studi literatur, dimulai dengan menyusun model matematis dari permasalahan kemudian menyelesaikan permasalahan tersebut dengan metode Algoritma Genetika. Untuk melihat apakah metode yang digunakan sudah cukup baik dilakukan perbandingan hasil dari penelitian sebelumnya. Adapun langkah-langkah penelitian sebagai berikut:

\section{Model Matematis}

Langkah pertama dalam penelitian ini adalah menyusun pemodelan matematis terkait Flexible Job Shop dengan fungsi tujuan setiap pekerjaan selesai pada rentang waktu tertentu (due windows). Pada penelitian ini pekerjaan masing-masing memiliki interval waktu dimana pekerjaan diharapkan dapat diselesaikan pada interval tersebut $\left\{d_{i}^{l}, d_{i}^{u}\right\}$. Apabila pekerjaan diselesaikan diluar selang waktu tersebut maka akan diberikan penalti. Gambar 1 
menunjukkan $C_{1}$ menujukkan penyelesaian lebih cepat dari yang ditentukan, sementara $C_{2}$ menjukkan penyelesaian yang dilakukan melewati batas waktu.

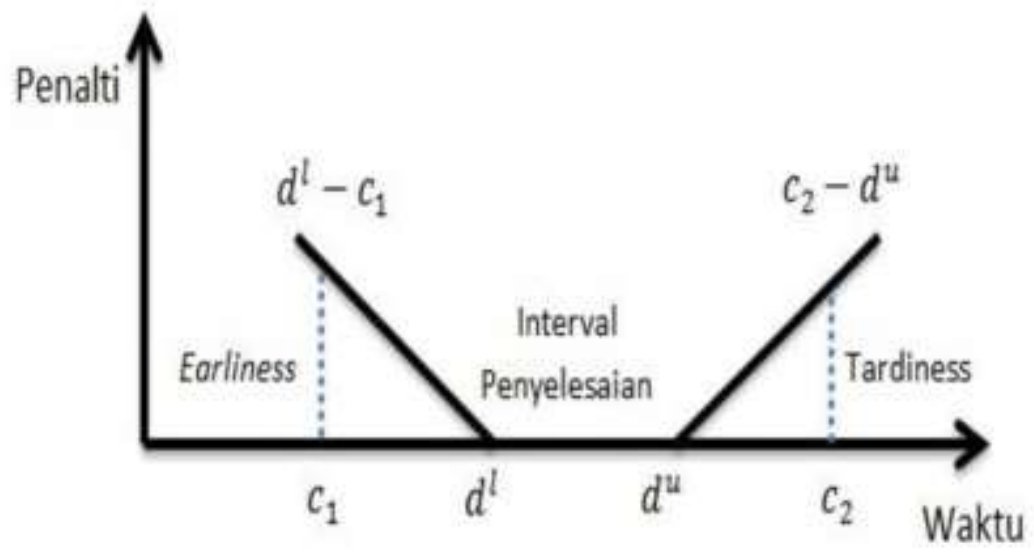

Gambar 1 Due Windows

Kendala-kendala dari penjadwalan flexible job shop harus memenuhi kriteria-kriteria dari job shop, menurut (Kuhpfahl, 2015) sebagai berikut:

1. Setiap mesin hanya dapat memproses satu pekerjaan dalam suatu waktu interval

2. Setiap operasi pada tiap pekerjaan harus dikerjakan secara berurutan

3. Setiap operasi hanya dapat diselesaikan oleh satu buah mesin tanpa delay

4. Operasi yang berbeda pada suatu pekerjaan tidak dapat dikerjakan bersamaan.

\section{Penyelesaian Dengan Algoritma Genetika}

Langkah-langkah penyelesaian Algoritma Genetika yaitu inisialisasi populasi, nilai fitness, seleksi, persilangan dan mutasi. Inisialisasi populasi dilakukan dengan membangkitkan beberapa kromosom urutan pekerjaan dan kromosom penugasan mesin. Bentuk kromosom seperti penelitian (Bierwirth, 1995). Kromosom-kromosom tersebut akan dimunculkan berdasarkan metode heuristik sederhana. Kromsom penugasan mesin berdasarkan (Kacem, Hammadi, \& Borne, 2002) .Kromsom urutan pekerjaan menggunakan dispatching rule (Michael, 2018) yaitu Most Operation work remaining, Most operation remaining Earliest due data dan Random.

Nilai fitness menghitung penalti due windows untuk tiap-tiap kromosom akan dihitung $(\mathrm{F}(\mathrm{x}))$. Semakin kecil nilai $\mathrm{F}(\mathrm{x})$ maka akan semakin baik kromosom tersebut. Dengan demikian nilai fitness adalah $f(x)=\frac{1}{F(x)}$. Kromosom terbaik akan disimpan untuk dimunculkan pada iterasi selanjutnya. Hal ini dilakukan agar kromosom tersebut tidak mengalami perubahan-perubahan pada langkah persilangan maupun mutasi.

Proses seleksi dilakukan dengan metode Roullete Wheel Selection yaitu dengan membangkitkan sembarang bilangan acak $r$ dan memilih kromosom yang memiliki nilai kumulatif individu lebih kecil dari $r$ untuk tetap bertahan. Proses persilangan dilakukan dengan mempertukarkan gen antara dua kromosom yaitu kromosom pendonor dan reseptor. Kedua kromosom ini akan disebut sebagai kromosm induk. Kromosom pendonor akan memberikan beberapan gen kepada kromosom reseptor sehingga menghasilkan anak (offspring) Proses mutasi adalah perubahan gen pada suatu kromosom sehingga 
menghasilkan kromosom baru. Karena penelitian ini merupakan Flexible Job Shop maka mutasi dilakukan secara dua tahap yaitu untuk urutan pekerjaan dan penugasan mesin seperti pada penelitian (Piroozfard, Wong, \& Wong, 2018). Proses ini akan dilakukan secara berulang-ulang sampai maksimum iterasi (MaxGen) tercapai. Berikut adalah flowchart Algoritma Genetika

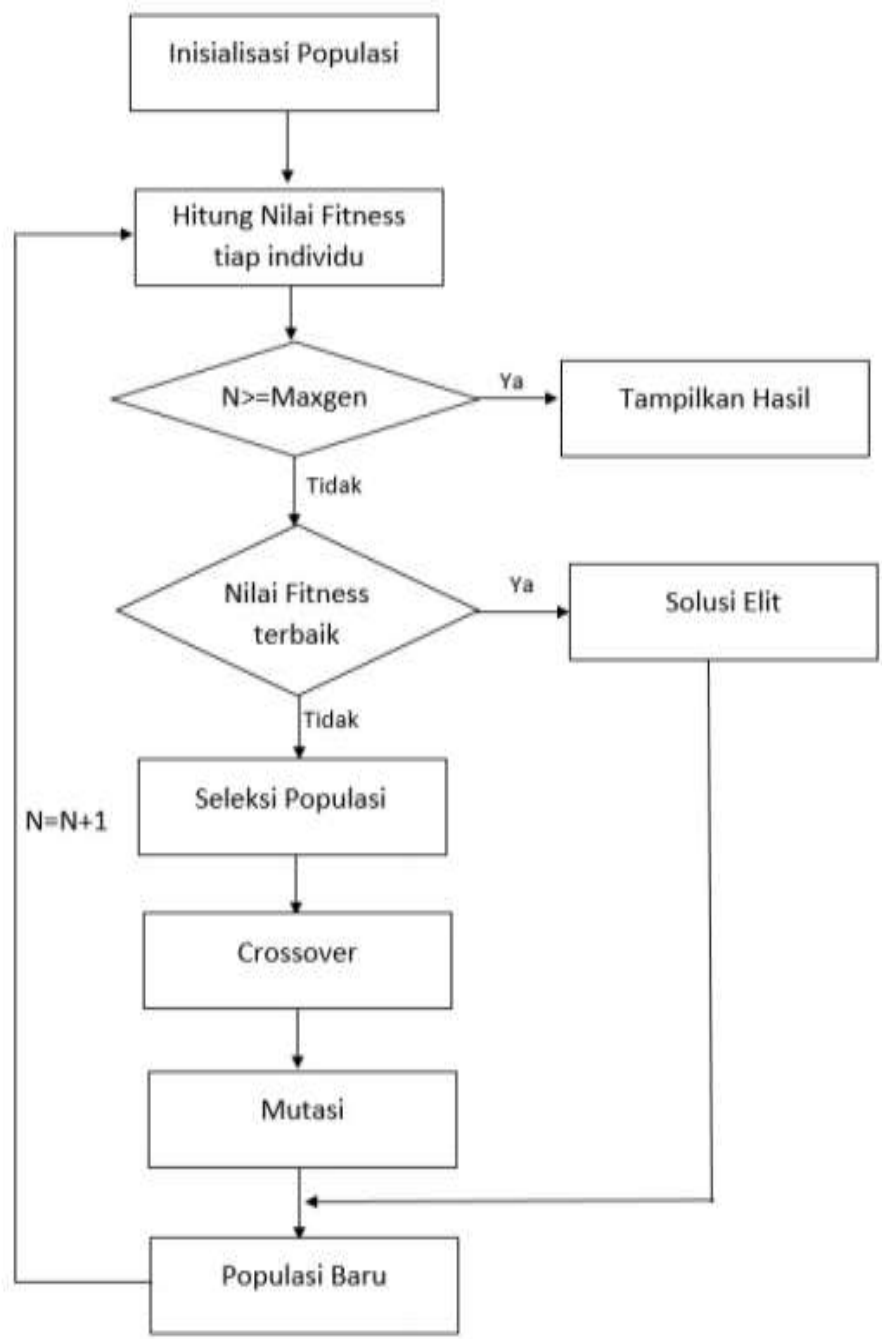

Gambar 2 Flowchart Algoritma Genetika

\section{Pengumpulan data dan Perbandingan Hasil}

Data yang digunakan adalah kasus Flexible Job Shop dari (L Yin, X Li, L Gao, C Lu, \& Z Zhang, 2017). Karena penelitian ini memiliki fungsi tujuan yang berbeda maka untuk menguji keakuratan algoritma ini, dilakukan perbandingan hasil untuk fungsi tujuan makespan. Semakin kecil hasil untuk makespan yang maka semakin baik performa algoritam tersebut. Sementara untuk due windows dilakukan penambahan data untuk $\left\{d_{i}^{l}, d_{i}^{u}\right\}$ pada tiap-tiap pekerjaan secara acak. Software yang digunakan adalah Matlab 2014a. Berikut adalah flowchart dari Algoritma Genetika 


\section{Hasil dan Pembahasan}

\section{Model Matematis}

Model matematis Mixed Integer Programming dengan fungsi tujuan meminumkan due windows adalah sebagai berikut:

Notasi yang digunakan

$i, g \quad:$ indeks job, $i=1 \ldots, n, g=1 \ldots, n$

$j, h \quad:$ indeks operasi $j=1 . ., m, h=1 \ldots, m$

$k \quad$ : indeks operasi $k=1 . ., o$

$p_{i j k} \quad$ : waktu pemerosesan untuk operasi $O_{i j}$ dengan mesin- $k$

$d_{i}^{u} \quad$ : batas atas waktu penyelesaian pekerjaan ke-i

$d_{i}^{l} \quad$ : batas bawah waktu penyelesaian pekerjaan ke-i

$T_{i} \quad$ : tardiness pekerjaan ke-i, $i=1 . ., n$

$E_{i} \quad:$ earliness pekerjaan ke-i,,$i=1 . ., n$

$c_{i j} \quad$ : waktu penyelesaian operasi $O_{i j}$

$c_{k} \quad$ : waktu penyelesaian operasi terakhir pada mesin ke-k

$w_{e} \quad$ : penalti untuk earliness

$w_{t} \quad$ : penalti untuk tardiness

Variabel biner yaitu

$x_{i j k}=\left\{\begin{array}{cl}1, & \text { operasi } O_{i j} \text { diselesaikan dengan mesin }-\mathrm{k} \\ 0, & \text { lainnya }\end{array}\right.$

Fungsi tujuan dan kendala

$\min D=w_{e} \sum_{i=1}^{n} E_{i}+w_{t} \sum_{i=1}^{n} T_{i}$

Kendala

$$
\begin{aligned}
& \sum_{k=1}^{o} x_{i j k}=1 \quad \forall \mathrm{i}, \mathrm{j} \\
& c_{k} \geq c_{i j} \cdot x_{i j k} \\
& n \\
& T_{i}=\max _{i=1}^{n}\left\{0, c_{i}-d_{i}^{u}\right\} \\
& E_{i}=\max _{i=1}^{n}\left\{d_{i}^{l}-c_{i}, 0\right\} \\
& \quad n \\
& c_{i}=\max _{i=1}\left\{c_{i j}\right\} \\
& c_{i j}=s_{i j}+\left(p_{i j k}+x_{i j k}\right) \quad \forall \mathrm{i}, \mathrm{j}, \mathrm{k}
\end{aligned}
$$


$c_{i j} \leq s_{i(j+1)} \quad \forall \mathrm{i}, \mathrm{j}$

$s_{i j}+p_{i j k} \leq s_{g h}+M\left(1-y_{i j g h k}\right) \forall \mathrm{i}, \mathrm{j}, \mathrm{g}, \mathrm{h}, \mathrm{k}$

$s_{g h}+p_{g h k} \leq s_{i j}+M y_{i j g h k} \quad \forall \mathrm{i}, \mathrm{j}, \mathrm{g}, \mathrm{h}, \mathrm{k}$

$s_{i j} \geq 0, s_{g h} \geq 0, c_{i j} \geq 0$

Persamaan (1) menunjukkan fungsi tujuan meminimumkan due windows, kendala (2) memastikan tiap operasi diselesaikan oleh satu buah mesin, kendala (3) menunjukkan waktu pemerosesan operasi terakhir pada mesin, kendala (4) dan (5) menujukkan perhitungan untuk tardiness dan earliness, dimana nilai keduanya harus bernnilai positif, kendala (6) menunjukkan waktu penyelesaian pekerjaan yaitu waktu pemerosesan terbesar untuk pekerjaan tersebut, kendala (7) menunjukkan waktu penyelesaian operasi adalah penjumlahan waktu operasi mulai dikerjakan dan waktu pemerosesan, kendala (8) menunjukkan setiap operasi harus dikerjakan secara berurutan, kendala (9) dan (10) memastikan tiap mesin hanya dapat memroses suatu pekerjaan dalam suatu selang waktu

\section{Penyelesaian dengan Algoritma Genetika}

Data waktu pemerosesan mesin diproleh dari (Lvjiang Yin, Xinyu Li, Liang Gao, Chao $\mathrm{Lu}, \&$ Zhao Zhang, 2017)dengan penambahan data untuk rentang waktu keterlambatan due windows, $\boldsymbol{D}_{\boldsymbol{l}}$ untuk earliness dan $\boldsymbol{D}_{\boldsymbol{u}}$ untuk tardiness, maka persoalan yang akan diselesaikan seperti pada tabel 4.1

Tabel 1 Kasus 4 Job dan 5 Mesin

\begin{tabular}{ccccccccc}
\hline Job & Operasi & $\boldsymbol{M}_{\mathbf{1}}$ & $\boldsymbol{M}_{\mathbf{2}}$ & $\boldsymbol{M}_{\mathbf{3}}$ & $\boldsymbol{M}_{\mathbf{4}}$ & $\boldsymbol{M}_{\mathbf{5}}$ & $\boldsymbol{D}_{\boldsymbol{l}}$ & $\boldsymbol{D}_{\boldsymbol{u}}$ \\
\hline $\boldsymbol{J}_{\mathbf{1}}$ & $O_{11}$ & 9 & 6 & - & 12 & - & 10 & 12 \\
\hline & $O_{12}$ & - & - & 6 & - & 7 & & \\
\hline $\boldsymbol{J}_{\mathbf{2}}$ & $O_{13}$ & - & 2 & 4 & - & - & & \\
\hline & $O_{21}$ & 5 & - & - & 7 & 9 & 7 & 12 \\
\hline & $O_{22}$ & - & 4 & 6 & 8 & - & & \\
\hline $\boldsymbol{J}_{3}$ & $O_{23}$ & - & - & 4 & - & 8 & & \\
\hline & $O_{31}$ & 3 & - & - & - & - & 8 & 13 \\
\hline & $O_{32}$ & - & 3 & - & 5 & - & & \\
\hline $\boldsymbol{J}_{4}$ & $O_{33}$ & 8 & - & 10 & - & 13 & & \\
\hline & $O_{41}$ & 6 & - & 9 & - & 10 & 9 & 12 \\
\hline & $O_{42}$ & - & 3 & - & - & - & & \\
\hline
\end{tabular}

Untuk memastikan program sudah berjalan dengan baik, dilakukan pengujian dengan menggunakan penelitian (Lvjiang Yin et al., 2017) sebagai perbandingan untuk kasus single objective makespan. Parameter yang digunakan adalah, jumlah populasi $=200$, jumlah 
iteras $i=100$, probabilitas persilangan $=0,9$, probabilitas mutasi $=0,8$, dan probabilitas elit $=0,1$ Pada penelitian ini diproleh hasil 17 yang mana sama dengan hasil pada penelitian tersebut.

Untuk penyelesaian due windows dilakukan pada beberapa kombinasi bobot untuk earliness $\left(W_{e}\right)$ dan bobot untuk tardiness $\left(W_{t}\right)$. Berikut hasil yang diproleh

Tabel 2 Kasus 4 Job dan 5 Mesin

\begin{tabular}{cll}
\hline Bobot & $\begin{array}{l}\text { Due } \\
\text { Windows }\end{array}$ & Makespan \\
\hline $\boldsymbol{W}_{\boldsymbol{e}}=\mathbf{0 , 2 5} ; \boldsymbol{W}_{\boldsymbol{t}}=\mathbf{0 , 7 5}$ & 11,25 & 20 \\
\hline $\boldsymbol{W}_{\boldsymbol{e}}=\mathbf{0 , 5} ; \boldsymbol{W}_{\boldsymbol{t}}=\mathbf{0 , 5}$ & 7,5 & 20 \\
\hline $\boldsymbol{W}_{\boldsymbol{e}}=\mathbf{0 , 7 5} ; \boldsymbol{W}_{\boldsymbol{t}}=\mathbf{0 , 2 5}$ & 3,75 & 20 \\
\hline
\end{tabular}

Dari tabel terlihat penalti terkecil diproleh pada $W_{e}=0,75 ; W_{t}=0,25$. Hal ini terjadi karena penalti yang diberikan apabila pengerjaan terlambat lebih besar daripada pengerjaan yang terlalu cepat. Bentuk Gantt Chart untuk permasalahan tersebut adalah sebagai berikut.

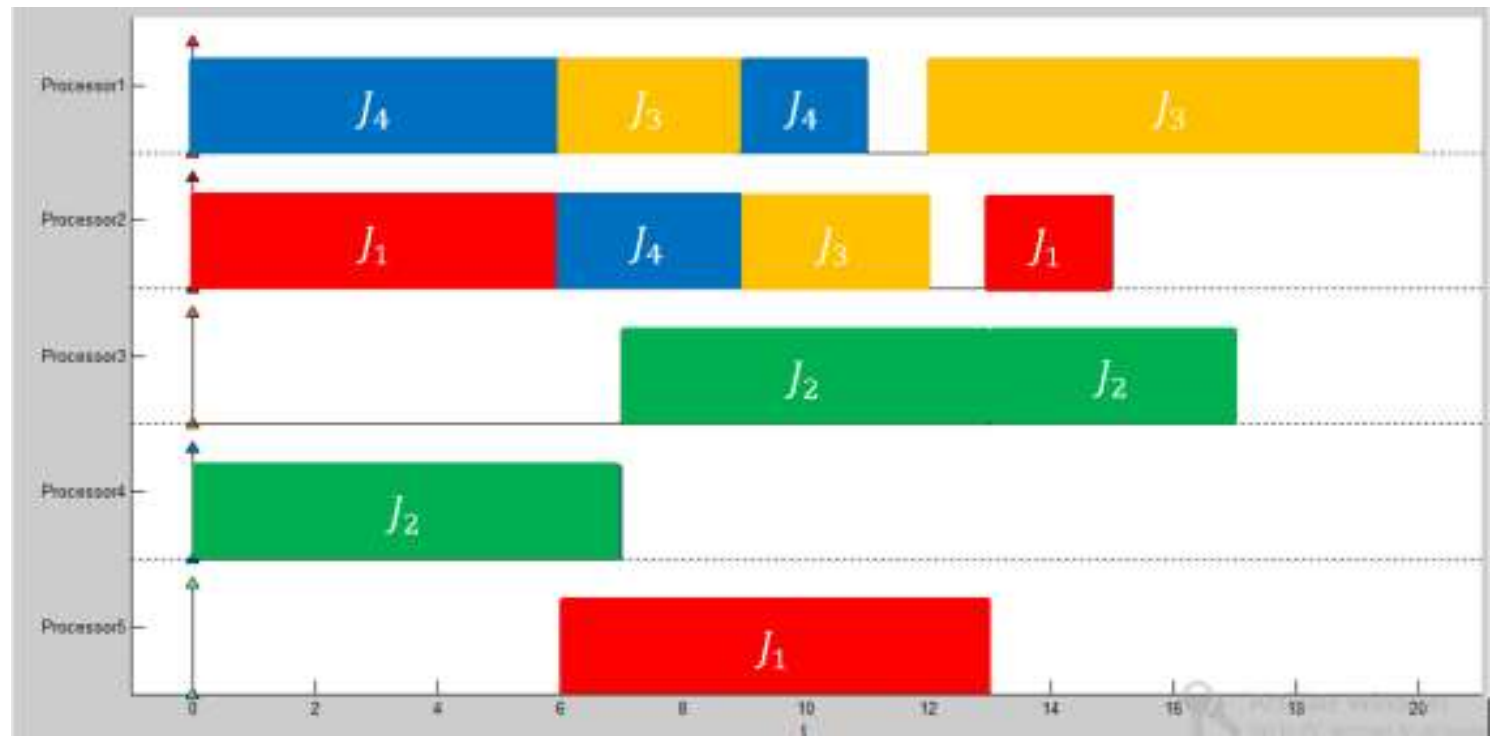

\section{Gambar 3 Gantt Chart}

Jika dilihat pada diagram Gantt Chart due windows juga berkaitan erat dengan nilai makespan, semakin kecil due windows yang didapat maka semakin kecil nilai makespan yang diproleh. Dari gambar terlihat hanya pekerjaan $\boldsymbol{J}_{\mathbf{2}}$ dan $\boldsymbol{J}_{\mathbf{4}}$ yang waktu penyelesaiannya berada pada selang waktu yang diberikan. $\boldsymbol{J}_{2}$ diselesaikan pada waktu 11 , sehingga berada pada rentang $\{7,12\}$, sementara $\boldsymbol{J}_{4}$ diselesaikan pada waktu 11 berada pada rentang $\{9,12\}$

\section{Kesimpulan}

Due Windows menjadi alternatif untuk Penjadwalan Flexible Job Shop terkait dengan penyelesaian pekerjaan. Selang waktu yang diberikan memberikan toleransi pada penyelesaian pekerjaan sehingga lebih sesuai dengan kehidupan sehari-hari. Performa dari 
Algoritma Genetika cukup baik dalam menyelesaikan kasus Flexibel Job Shop, terbukti hasil yang cukup baik terkait dengan hasil makespan. Penelitian ini dapat dikembangkan dengan melakukan penggabungan algoritma (hybrid) untuk hasil yang lebih baik. 


\section{Bibliografi}

Ahmadi, E., Zandieh, M., Farrokh, M., \& Emami, S. M. (2016). A multi objective optimization approach for flexible job shop scheduling problem under random machine breakdown by evolutionary algorithms. Computers \& Operations Research, $73,56-66$.

Ahmadian, M. M., Salehipour, A., \& Cheng, T. (2021). A meta-heuristic to solve the just-intime job-shop scheduling problem. European Journal of Operational Research, 288(1), 14-29.

Alzahrani, J. S. (2019). Job Shop Scheduling Considering Makespan, Penalties Of Machine Idling, And Job Out Of Time. International Journal of Research-Granthaalayah, $7(1), 73-82$.

Amjad, M. K., Butt, S. I., Kousar, R., Ahmad, R., Agha, M. H., Faping, Z., . . Asgher, U. (2018). Recent research trends in genetic algorithm based flexible job shop scheduling problems. Mathematical Problems in Engineering, 2018.

Bierwirth, C. (1995). A generalized permutation approach to job shop scheduling with genetic algorithms. Operations-Research-Spektrum, 17(2), 87-92.

Idowu, G. A., Adamu, M. O., \& Sawyerr, B. S. (2020). Hybrid Metaheuristic for Just In Time Scheduling in a Flow Shop with Distinct Time Windows. International Journal of Mathematical Sciences and Optimization: Theory and Applications, 2020(1), 741756.

Kacem, I., Hammadi, S., \& Borne, P. (2002). Approach by localization and multiobjective evolutionary optimization for flexible job-shop scheduling problems. IEEE Transactions on Systems, Man, and Cybernetics, Part C (Applications and Reviews), $32(1), 1-13$.

Kim, J.-G., Jun, H.-B., Bang, J.-Y., Shin, J.-H., \& Choi, S.-H. (2020). Minimizing Tardiness Penalty Costs in Job Shop Scheduling under Maximum Allowable Tardiness. Processes, 8(11), 1398.

Kuhpfahl, J. (2015). Job shop scheduling with consideration of due dates: Potentials of local search based solution techniques: Springer.

Lin, S.-S. (2020). Due-Window Assignment and Resource Allocation Scheduling with Truncated Learning Effect and Position-Dependent Weights. Discrete Dynamics in Nature and Society, 2020.

Marzouki, B., Driss, O. B., \& Ghédira, K. (2018). .Solving distributed and flexible job shop scheduling problem using a chemical reaction optimization metaheuristic. Procedia Computer Science 126, 1424-1433.

Michael, L. P. (2018). Scheduling: theory, algorithms, and systems: Springer.

Piroozfard, H., Wong, K. Y., \& Wong, W. P. (2018). Minimizing total carbon footprint and 
total late work criterion in flexible job shop scheduling by using an improved multiobjective genetic algorithm. Resources, Conservation and Recycling, 128, 267-283.

Saudagar, S., Kamboj, A., Mohan, N., Patil, S., \& Powar, N. (2020). Resource Allocation and Task Scheduling with Skill Level and Time Bound Constraints. International Journal of Industrial and Manufacturing Engineering, 14(9), 732-738.

Yin, L., Li, X., Gao, L., Lu, C., \& Zhang, Z. (2017). A novel mathematical model and multiobjective method for the low-carbon flexible job shop scheduling problem. Sustainable Computing: Informatics and Systems 13, 15-30. 